\title{
A perspective Study on oral-fecal transmission of COVID-19, its
}

\section{Prevention and Management}

\section{Running title: oral fecal transmission of COVID-19}

Abdullah $^{1,3 *}$, Shah Faisal ${ }^{2}$, Anees ur Rahman ${ }^{3}$, Baseerat bibi $^{4}$, Hania ishaq $^{5}$

${ }^{1}$ Department of Microbiology,Abdul Wali Khan University Mardan, KPK, Pakistan.

${ }^{2}$ Department of Biotechnology, Bacha Khan University Charsadda Khyber Pakhtunkhwa.

${ }^{3}$ Department of Microbiology,Abasyn University Peshawar, KPK, Pakistan.

${ }^{4}$ Department of Zoology, Shaheed Benazir Bhutto Women University Peshawar, KPK, Pakistan.

${ }^{5}$ Department of Botany, PMAS Arid Agriculture University Rawalpindi, Islamabad, Pakistan.

*Corresponding Author: Mr. Abdullah, Department of Microbiology Abdul Wali khan University, Mardan 2300, Kpk, Pakistan. Email: Abdul.9353chd@gmail.com. Tel: +923159353056 


\section{ABSTRACT}

The novel coronavirus outbreak arose in Wuhan, China in Dec, 2019. It is declared the $6^{\text {th }}$ public health emergency by the WHO and named as COVID-19. SARS-CoV-2 is nonsegmented positive sense ssRNA virus, belongs to the Coronaviridae under the Nidovirales and spread largely in human being and other mammals. Person to person, airborne and surface transmission is common, the virus get entered to host through nose, mouth, eyes, food, water and feces. An infected patients can transmit the virus to 2.2 healthy individuals. A patient in the US showed gastrointestinal symptoms vomiting, nausea and pass loose stools. Later the patient declared positive for SARS-CoV2 on the basis of viral detection in stools and respiratory samples. The gastrointestinal symptoms like diarrhea, nausea, vomiting, abdominal discomfort and detection of SARS-CoV-2 in stools of infected and recovered patients indicates potential oralfecal transmission route, it could be potential risk for the spread of COVID-19. The flatus is gas produced by aerophagia or bacterial fermentation in intestine and expelled out through esophagus or anus. It consists of Hydrogen, Oxygen, Nitrogen, Carbon dioxide and Methane, their percentage composition is $99 \%$. Previous study showed that bacteria can transmit through barebottom farting. The gastrointestinal manifestation and possible oral-fecal transmission, the flatulence could be the risk of transmission for COVID-19. Personal hygiene must be adapted to prevent the spread of disease.

Keywords: Flatulence; Aerophagia; COVID-19; Transmission; SARS-CoV-2; Farting; Middle east respiratory syndrome; Prevention; Management.

\section{SUMMARY}

\section{Introduction}

2. Transmission

3. Person to person transmission

4. Oral-fecal transmission

5. Flatulence

6. Mechanism of production of flatus

7. Is Flatulence presents any Risk of

Transmission for COVID-19?

8. Prevention and Management

9. Conclusion

\section{Abbreviations}

Coronavirus disease 2019 (COVID-19); Severe acute respiratory syndrome (SARS); Ultra computed tomography (UCT); Middle East respiratory syndrome (MERS); Coronaviruses (CoVs); Centre for disease control and prevention (CDC). 


\section{INTRODUCTION}

The novel coronavirus outbreak arose in Wuhan China in Dec, 2019. As of April 27, 2020, a total 2.98 million positive cases and 207 thousand deaths has been registered worldwide. The mortality rate of SARSCoV-2 is less than SARS-CoV and MERS. According to the China CDC, by Feb 16, 2020, there had been 70641 confirmed cases of COVID-19 and 1772 deaths, with an average mortality rate of about $2 \cdot 5 \%{ }^{1}$. Which is less than mortality rate of the MERS $(34.40 \%) \& \operatorname{SARS}-\operatorname{CoV}(9.19 \%)^{2}$, figure 1. Recent studies revealed that respiratory symptoms of COVID-19 including fever cough and dyspnea are similar to SAR-CoV outbreak and MERS. The frequency of typical gastrointestinal feature like vomiting, nausea, diarrhea and abdominal aches significantly differs between distinct studied populations, however these symptoms are mild and followed by relative respiratory sign and symptoms ${ }^{3}$. Evidences are there from past studies of SARS indicating the gastrointestinal tropism of SARS-CoV was confirmed by viral presence in stools and biopsy of infected and recovered individuals, may give partial explanation for the gastrointestinal manifestation and dissemination of $\mathrm{SARS}^{4}$. It was confirmed by the 2-day history of a patient in the US, on the time of admission vomiting and nausea were reported, and on the second day he passed a loose stools in hospital. Later the patient declared positive of SARS-CoV-2 on the basis of viral detection in stools and respiratory specimens ${ }^{5}$. 2019-nCoV nucleic acids were also detected in salivary samples of diseased individuals rather than aspirate from naso-pharynx, later the decline viral abundance was also reported in saliva after attending hospital ${ }^{6}$.

Taken in to consideration a number of growing clinical evidences revealed that digestive system may assist as a substitute way for infection in individuals in proximity with untamed and suffered animals. However, the individuals with mild symptoms or asymptomatic have been ignored in former studies. So doctors should take care and investigate the individuals with mild and prime gastrointestinal manifestations and note the time span of infection to late viral transformation. The cases of severe acute respiratory syndrome are increasing day by day and the whole world confronting the pandemic Covid-19. Shown in figure 2. 


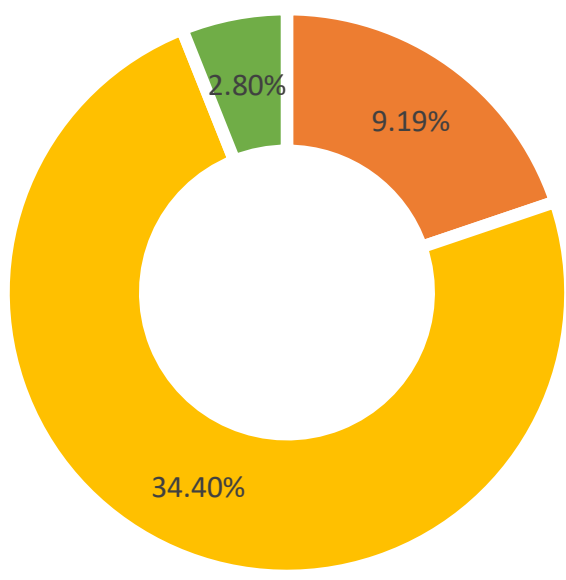

- SARS-CoV-1 - MERS-CoV - SARS-CoV-2

Figure 1: Mortality rate of SARS-CoV-1, SARS-CoV-2 and MERS coronavirus

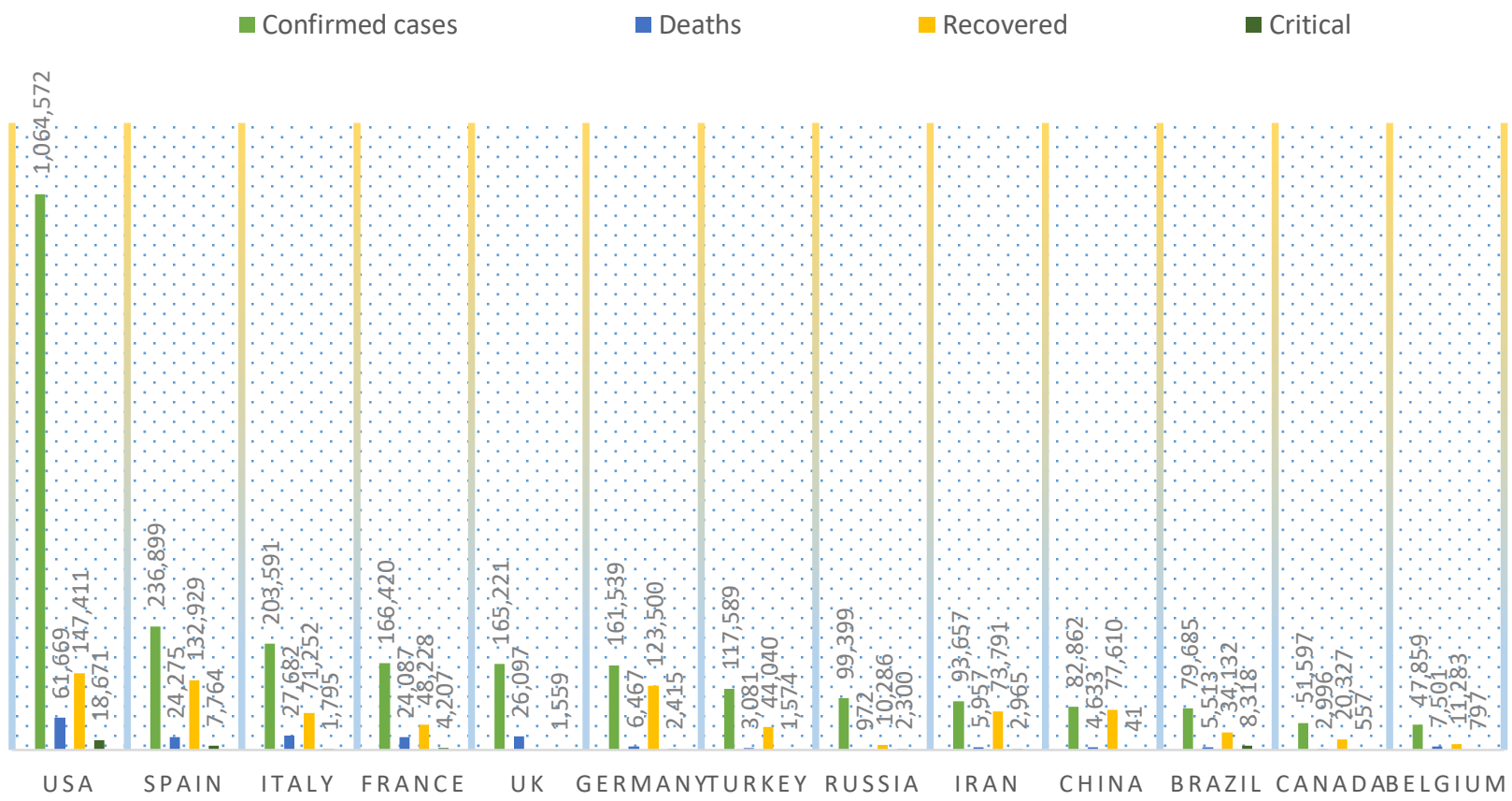

Figure 2: As of March 30, 2020. These are the top 14 Countries of the world having highest number of confirmed cases. 


\section{Transmission}

As the first case reported in Wuhan china so it is said that this virus came from Hunan Seafood Wholesale Market situated in Wuhan, but there is still no evidence. Human to human transmission is common as according to the CDC and $\mathrm{WHO}$, it was obvious that close contact is the major facilitator to transmit COVID-19 infection. The virus travel upto one meter in air and contracted by the person who is in close proximity to the infected person. From the analysis of the investigations and research conducted by the China CDC, the incubation period could be 3 to 7 days or may up to 2 weeks ${ }^{7}$. It was also concluded from the data that within every seven days this novel SARS-CoV-2 doubles its progeny and the reproduction number is $R_{0}$ is 2.2 , simply each patient can transmits the infection to an extra 2.2 individuals shown in figure 3. On the other hand if we compare SARS-CoV with SARS-CoV-2 the Reproduction rate of the SARS-CoV epidemicwere approximately 3 in 2002-2003 .

\section{Person to Person Transmission}

Experts believe that all routes of transmission for CoVID-19 are possible but in novel coronavirus the person to person transmission is very common ${ }^{9}$. This can happen by many ways: when an infected person with corona virus coughs, talk or sneeze in a close proximity with healthy individuals of about 6 feet distance ${ }^{10}$. The healthy one get the virus in to his lungs by nose or mouth and get infected. Recent studies revealed that $\mathrm{nCoV}-19$ can live in air for up to 3 hours ${ }^{11}$. This virus floating in air and contaminate the air for healthy individuals. Another way of transmission is surface transmission in which a patient cough or sneeze on. The virus can live on plastic and stainless steel surfaces for up to 2-3 days.

\section{Oral-Fecal Transmission}

Studies also suggest that the fecaloral could be a potential route of transmission. The virus has been detected in stools of infected patients ${ }^{12}$. Attending washroom without hand washing spread the virus. Symptomatic patients often spread the virus. But asymptomatic cases are alarming due to no sign and symptoms and act as a free vectors, they don't know they've been infected and pass the virus to other easily ${ }^{13}$. Pre-symptomatic spread pass virus to other before noticing any signs and symptoms of infection. Community spread is also common in which person didn't know from where and whom he infected ${ }^{14}$. 


\section{How a virus with a reproduction number (R0) of 2 spreads}

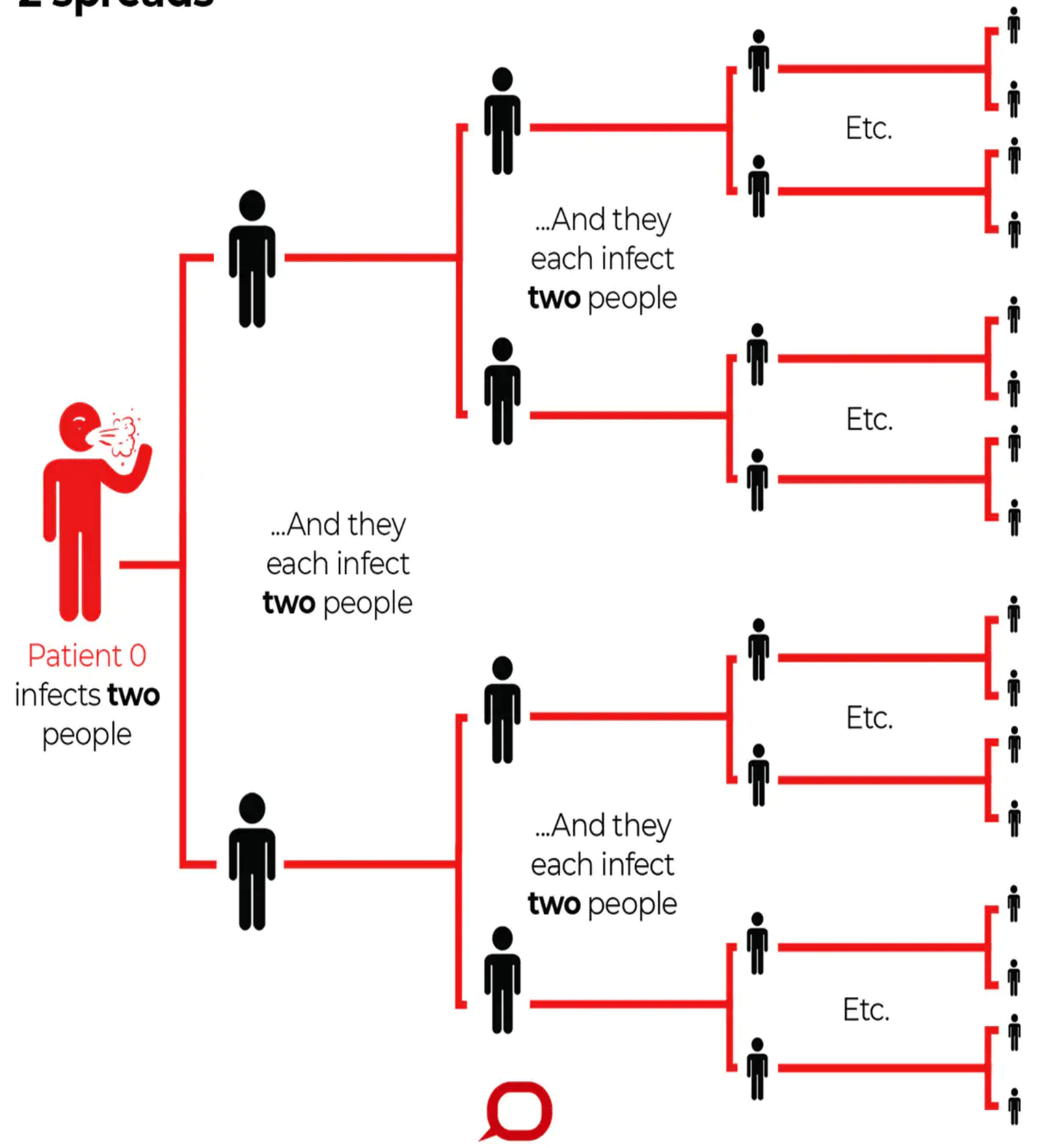

Figure 3: Reproduction number and transfer rate of COVID-19

(Source: https://ivoryembassy.com/blog/r0-of-covid-19) 


\section{Flatulence}

State of being flatulent is called Flatulence. Medically gas generated in the stomach or in large and small bowels is termed as Flatus ${ }^{15}$. These are the gases generated in intestine due to digestive problems or inhaled air during eating food, thus Flatus is not totally produces in the stomach or GI tract but a proportion of environmental air oxygen and nitrogen may be swollen can cause intestinal gas ${ }^{16}$. Volume or frequency of flatus differs between individuals, but it's common to pass flatus and the feculent odor is normal for intestinal $\operatorname{gas}^{17}$. By the pressure of muscular layer surrounds the intestine the Flatus is brought to the rectum to be expelled out. The blowing noise of flatulence is created by the anal aperture and buttocks acting together in a manner similar to wind instrument (embouchure) that produce sound. The sound and the odor both are considered root of ashamed, anger or comedy ${ }^{18}$. Common symptoms linked to intestinal gas, the primary symptoms linked to intestinal gas are; aches in the anal and area around abdomen, Stuffed feeling and abdominal discomfort, excessive flatus volume and smell, lack of voluntary control over gas. Moreover, sometimes belching or eructation (act of air expelling from the stomach via mouth) also known as burping considered as flatulence ${ }^{19}$. Furthermore, in health disorders like lactose intolerance, irritable bowel syndrome and celiac disease, the excessive flatus can be a $\operatorname{sign}{ }^{20}$.

\section{Mechanism of Production of Flatus}

Bacterial fermentation in the gastrointestinal tract is the main production source of flatus, released as a byproduct especially during the fermentation occurring in colon ${ }^{21}$. There are rare considering reports of aerophagia causing intestinal gas ${ }^{22}$. The following four events are responsible for the production of naturally occurring gas in gastrointestinal tract ${ }^{23}$. Aerophagia, Gastric acid interaction with alkaline food, pancreatic bicarbonate and saliva, Diffusion of Oxygen, carbon dioxide and nitrogen from blood, Bacterial metabolism and fermentation process. The produced Gases are removed by either diffuse into blood and consumed by bacteria or expel out through esophagus or anus. Primarily aerophagia is considered for gas production in GI tract ${ }^{22}$ during meal environmental air is swallowed. UCT (ultrafast computed tomography) in humans revealed that $17 \mathrm{ml}$ of air get swallowed with drinking $10 \mathrm{ml}$ of water ${ }^{24}$. Every day large amount of air reaches to stomach with given food (solid or liquid) that 
taken in to mouth all day. The $\mathrm{N}_{2}$ component of swallowed air is then passed through rectum, if not blenched ${ }^{25}$. Vigorous exercise and rapid eating habit increase the risk of aerophagia however some air also ingest with the propulsions of bolus through pharynx. Within 15 to 35 minutes flatus is produced in stomach by aerophagia ${ }^{25}$. Gases can travel at velocity or speed up to $10 \mathrm{~cm} / \mathrm{sec}$ through the gasterointestinal tract however the intestinal transit time is longer for liquids and solids compared to gasses. Production of $\mathrm{CO}_{2}$ occurred in stomach by the interaction of HCL with alkaline food, saliva and bicarbonates present in pancreatic juice ${ }^{26}$. Swallowed air plus variable quantities of $\mathrm{CO}_{2}$ constitutes belched air however bacterial fermentation can also produce large amount of gas in the colon. Fiber, poorly digestible protein, carbohydrates, mucin, bile acids are the substrates for bacterial fermentation to produce gas. Non-digestible oligosaccharides raffinose, stachyose, verbacose are more likely to generate more gas in intestine ${ }^{25,26}$. Composition of flatus consists of gasses over 99\% of the whole composition including hydrogen, oxygen, nitrogen, carbondioxide and methane gass, these all gasses are nonsmelly in nature ${ }^{24}$. Patients have problems of intense intestinal gas mainly consists of $\mathrm{N}_{2}{ }^{27}$. Nitrogen and oxygen are not produced in the
GI tract but it is from environmental air. $\mathrm{H}_{2}$, $\mathrm{CO}_{2}$ and $\mathrm{CH}_{4}$ are generated in the bowl and constitute $74 \%$ of the whole volume of flatus ${ }^{28}$ and $25 \% \mathrm{O}_{2}$ and $\mathrm{N}_{2}$ as shown in table 1. Flatus can got fire contains proper amounts of methane and hydrogen because of their flammable nature ${ }^{29}$. But not all humans produce methane containing flatus. For example, Miller et al, conducted study on 9 feces samples only 5 of them having archaea which is able of generating $\mathrm{CH}_{4}$ gas $^{30}$. As Archaea that oxidizing hydrogen into methane gas can enhance the metabolic capability to absorb fatty acids from food, thus presence of methane in human farts may correlate with obesity ${ }^{26}$.

The noxious smell of flatus in humans and animals strongly correlates with $\mathrm{H}_{2} \mathrm{~S}$ concentration $^{25}$. The trace compounds present in amount less than $1 \%$ give smell to flatus. Ammonia, indole, skatole and short chain fatty acids cause smell similar to flatus. Volatile sulfur compounds are the main contributor to the smell ${ }^{26}$. Methanethiol, hydrogen sulfide, dimethyl sulfide, di and trisulfide are found in flatus. Smell of volatile indole and skatol are noxious but don't contribute to flatus smell. 


\begin{tabular}{|c|c|c|c|}
\hline Type of gas & Percentage & Source & Volume \% \\
\hline Oxygen & \multirow{5}{*}{$99 \%$} & Aerophagia, diffusion from blood & \multirow{3}{*}{$74 \%$} \\
\hline Nitrogen & & Aerophagia, diffusion from blood & \\
\hline Hydrogen & & Bacterial fermentation in large intestine & \\
\hline Carbon dioxide & & $\begin{array}{l}\text { Diffusion from blood, Bacterial } \\
\text { fermentation (large intestine), Gastric } \\
\text { acid plus food, saliva, or bicarbonate }\end{array}$ & \multirow{2}{*}{$25 \%$} \\
\hline Methane & & Bacterial fermentation (large intestine) & \\
\hline
\end{tabular}

Table 2: Composition of Flatus

It is revealed by Levitt et al study that $\mathrm{H}_{2} \mathrm{~S}$, methyl mercaptan and dimethyl sulfide concentration have correlation with perceived bad smell of flatus respectively, subjecting pinto beans as a diet to stimulate flatus production ${ }^{31}$. It is also reported that methanethiol is the contributor to the flatus smell in those patients whose specific diet are not altered $^{32}$. It is now been revealed that methanethiol and $\mathrm{H}_{2} \mathrm{~S}$, are present in human flatus in concentrations above thresholds which increase the noxicity in smell ${ }^{33}$. Such smell can also be caused by bacterial micro flora in feces through fermentation in rectal canal. Sulfur containing amino acids increase the smell of flatus significantly.

\section{Is Flatulence presents any Risk of} Transmission for COVID-19?
Recently on Friday, 17th April, Dr. Norman Swan stated that bare-bottom farting should be avoided near each other as it could potentially spread the virus, he told in a live podocast "Coronacast" 34 . Dr. Andy Tagg tweeted a related question "can the bottombased emissions of someone with coronavirus be silent and deadly?" subjected to farts as a risk of transmission for COVID$19^{35}$. A hot discussion started on it and tagg give information about GI tract and flatulence $^{36}$. Tagg concluded that the SARSCoV-2 could potentially spread through farts. He linked his conclusion with the tang et al study that showed SARS-CoV-2 virus can be spread through feces and it has been detected in asymptomatic patients up to 17 days past the point of exposure ${ }^{37}$. A well-known 
epidemiologist Dr. Aaron E. Glatt ${ }^{38}$ wrote an email to The New York Post ${ }^{40}$ stating that studies revealed that there is significant percentage of covid-19 patients have gastrointestinal symptoms ${ }^{41}$. So farts could transmit it but there is no published data on it to confirm. However, among different study populations the incidence of nausea, diarrhea, vomiting and other abdominal discomforts varies significantly with early mild onset of respiratory symptoms ${ }^{42}$. Former studies of SARS-CoV indicated and verified viral detection in biopsy and stools specimen even in discharged patients ${ }^{43}$. Which may provide partial explanation that virus exists in stools and could be transmit through flatulence. Recently two Chinese laboratories reported live SARS-CoV-2 in stools samples of infected patients. Dr Karl Kruszelnicki designed his experiment to know whether the farting can contaminate the sterilize environment of operation theatre or not. For this he contacted to a microbiologist Mr. Luke Tennent and set up an experiment. He took two petri dishes and asked his colleague to break out wind directly into petri dishes at keeping 5 centimeters distance, first fully clothed and then with his trousers down. $\mathrm{He}$ lift the petri dishes overnight in an incubator.
The observation was shocking, the flatus that were directly pass to petri dishes with trousers down, sprout two types of bacteria one from gut and other from skin. No growth were observed in petri dish that were exposed to flatus wearing trouser. He concluded that wearing trouser acted as a filter that's why there is no growth observed in second petri plate. He further deducted that enteric zone observed in the first Petri dish was due to the flatus directly, fart blew some normal micro flora of buttocks skin blasted into petri dish. Further study revealed the observed bacteria were not harmful. So therefore it seems, that flatus may cause infection if the emitter is infected and naked, but not if he or she is clothed $^{44}$. Shown in figure 4.

Medical and health related professionals are cautioned about the new and interesting information and take it as a fact and evidence. While it's not something to believe so quickly but it needs some solid research to confirm farting as a risk for transmission of COVID-19. Regardless of the information whether or not farting is a risk for transmission of COVID-19, as the viral detection in feces confirmed so there is possibility that farting cold be the risk for transmission. 


\section{Dr Karl Kruszelnicki Experiment}

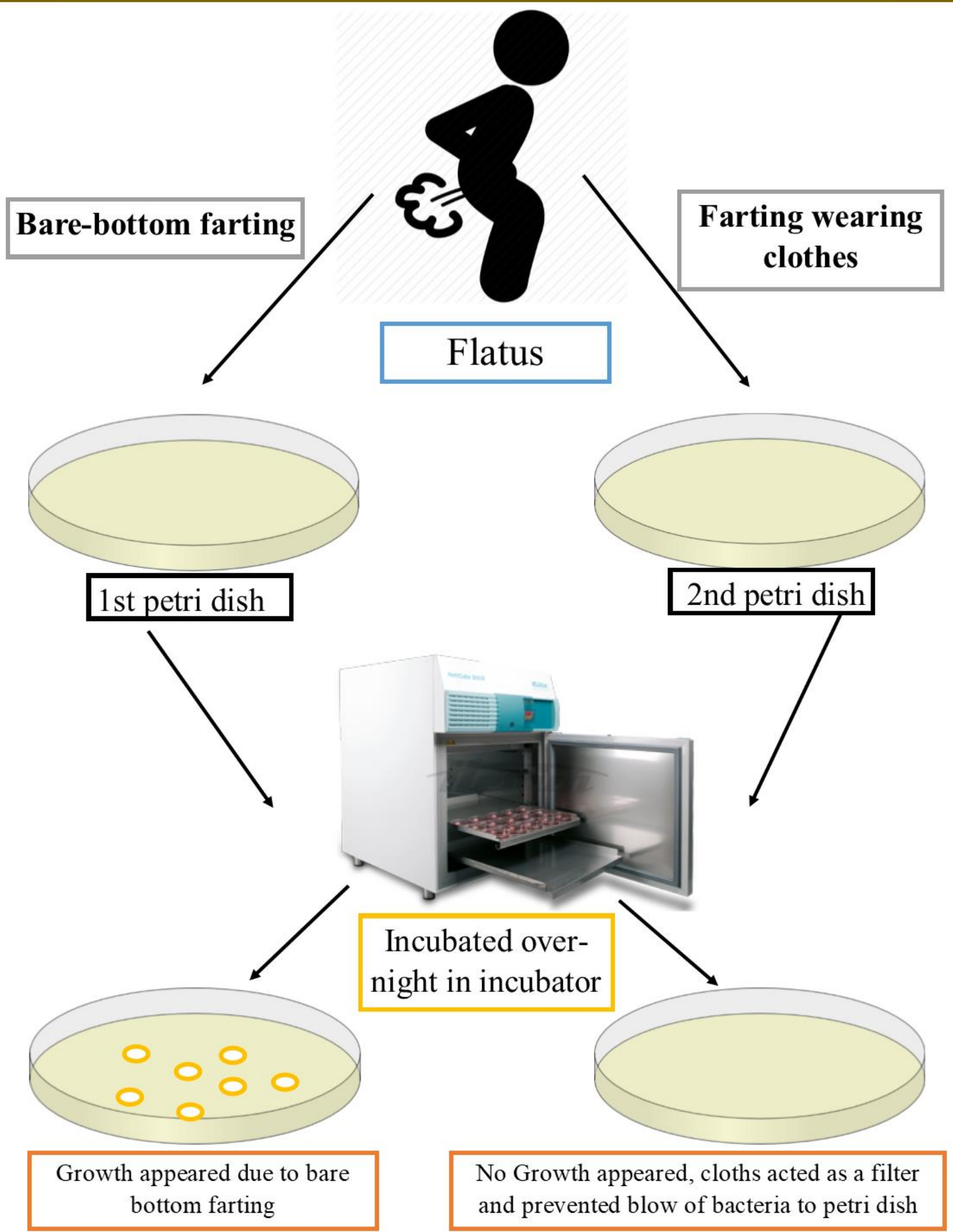

Figure 4: Dr karl experiment designed for to check bare-bottom farting transmit microbes or not. 
In the light of above discussion we all need good bathroom hygiene. The CDC reminds us that infectious diseases may spread in many ways; such as through mouth, nose, eyes, food, water, broken skin, genital fluids, sexual contact and even through feces.

\section{Prevention and Management}

1. Social distancing is the best way to slow down the spread of COVID-19. There are a few ways to do it ${ }^{45}$.

2. Avoid travel, don't get out of your home unnecessary, if going is must then wear a mask and keep 6 feet distance from others.

3. Avoid working in organization or company and if possible work from home.

\section{Avoid physical contact or visit with friends and family and use phone for communication $^{46}$.}

5. Make a habit of washing your hands before and after the meal for $20 \mathrm{sec}$ with soap, take a great care of washing your hands after attending toilet.

6. Avoid unnecessary shopping, groceries or drugs and other daily usage things should be ordered online.

7. Avoid close contact with pets, their waste and toys they touched.
8. Don't share your personal items like towels, utensils etc.

9. Clean and disinfect the surfaces frequently like phone, tables, doorknobs etc.

10. The infected peoples must be selfquarantine in a separate room to stop the spread of coronavirus to healthy individuals.

11. Gastrointestinal symptoms in COVID-19 infection such as diarrhea could be treated by available medicine used for it.

12. Bare-bottom farting should be avoided in close proximity with others in case of infection. So far, there is no vaccine for prevention of COVID-19, but some potential vaccines are being tested or under trail ${ }^{47}$ as shown in table 2 . These vaccine will be available soon to treat or prevent COVID-19 pandemic. Some experimental drugs are also being tested such as chloroquine and hydroxychloroquine ${ }^{48}$. Convalescent sera is the current available best option as there no vaccine so far ${ }^{49}$. If the situation get worsen call the doctor. Many countries around the world have limited large gatherings by closing markets, shopping malls, schools, universities, restaurants, and theaters ${ }^{50}$. These measures might be extreme. But according to health professionals it is the only way to slow down the spread of COVID-19. 


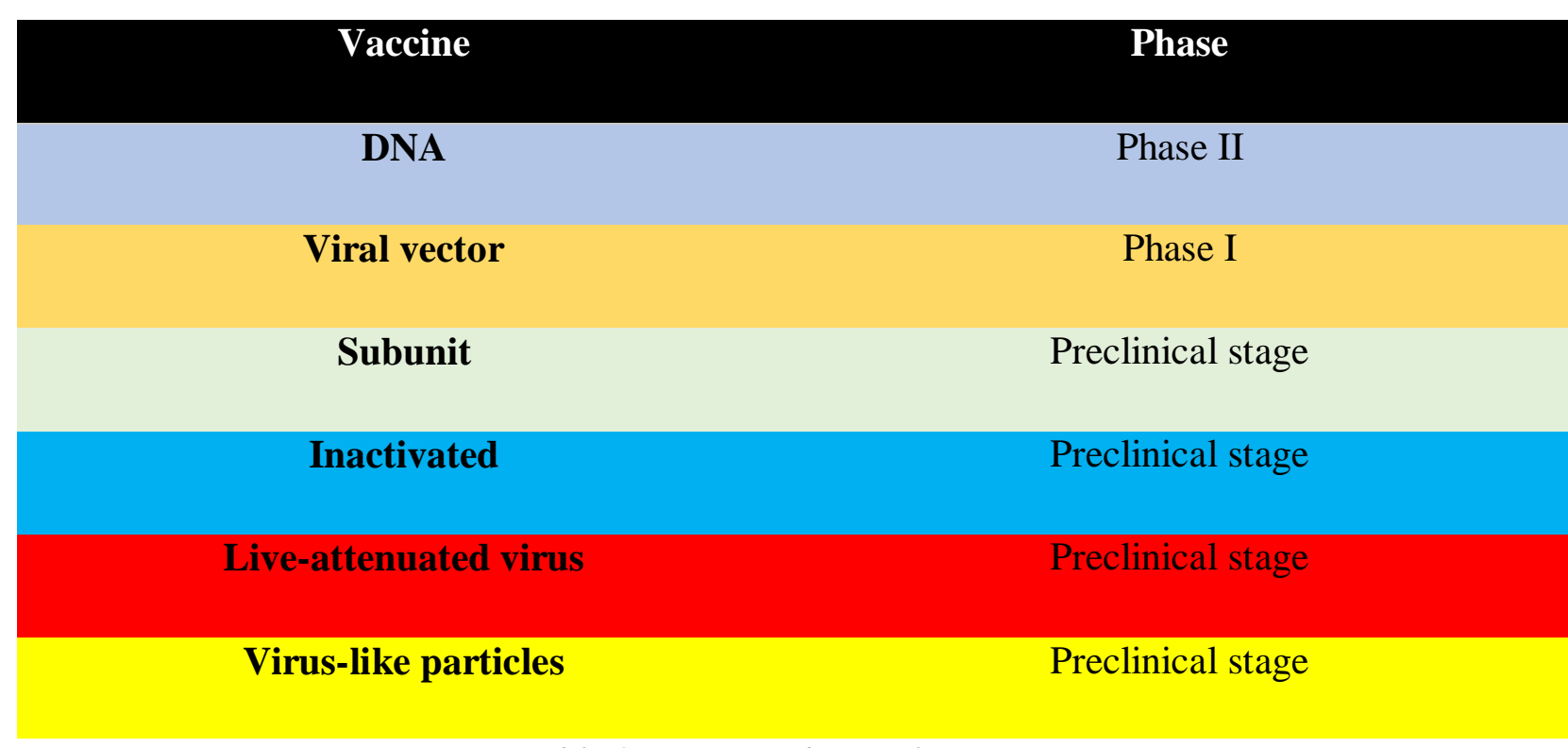

Table 2: Some under trail Vaccine

As still there are no vaccine but hopes are alive. Prevention is better than cure. We have only this option. By taking precautionary measures we can compete with COVID-19.

\section{Conclusion}

Diarrhea, vomiting and abdominal discomfort are frequent symptoms in patients infected with SARS-CoV-2. Increasing evidences and the detection of viral sequences in stools and gastrointestinal manifestations indicating the possible oralfecal transmission and this route of transmission could be potential risk. Asymptomatic spread is more alarming proper care to be needed. An infected person can transmit infection to 2 healthy individuals. Bacteria spreads through barebottom farting so the virus could be. Close contact with feces of human and animals and bare-bottom farting should be avoided. To minimize the oral-fecal transmission hands must be washed before and after attending toilet with soap for $20 \mathrm{sec}$. Moreover, the virus can live for hours on surface proper disinfection and prevention must be adapted. Keep social distancing and stay home, stay safe.

\section{Acknowledgments}

We are grateful to Dr. Hasnain jan for his kind support and help.

\section{Conflict of Interest}

Authors declare no conflict of interest 


\section{References}

1. Ji Y, Ma Z, Peppelenbosch MP, Pan Q. Potential association between COVID-19 mortality and health-care resource availability. The Lancet Global Health. 2020 Apr 1;8(4):e480.

2. Prompetchara E, Ketloy C, Palaga T. Immune responses in COVID-19 and potential vaccines: Lessons learned from SARS and MERS epidemic. Asian Pac J Allergy Immunol. 2020 Mar 1;38(1):1-9.

3. Wang, D., Hu, B., Hu, C. et al. Clinical characteristics of 138 hospitalized patients with 2019 novel coronavirus-infected pneumonia in Wuhan, China. ([published on February 7, 2020])JAMA. 2020;

4. Leung, W.K., To, K.F., Chan, P.K. et al. Enteric involvement of severe acute respiratory syndrome-associated coronavirus infection. Gastroenterology. 2003; 125 : 1011-1017
5. Holshue, M.L., DeBolt, C., Lindquist, S. et al. First case of 2019 novel coronavirus in the United States. N Engl J Med. 2020; 382: 929-936

6. To, K.K., Tsang, O.T., ChikYan Yip, C. et al. Consistent detection of 2019 novel coronavirus in saliva. ([published on February 12, 2020])Clin Infect Dis. 2020;

7. Leung, W.K., To, K.F., Chan, P.K. et al. Enteric involvement of severe acute respiratory syndrome-associated coronavirus infection. Gastroenterology. 2003; 125: 1011-1017

8. Bauch CT, Lloyd-Smith JO, Coffee MP, Galvani AP. Dynamically modeling SARS and other newly emerging respiratory illnesses: past, present, and future. Epidemiology. 2005 Nov;16(6):791-801.

9. Wang J, Tang K, Feng K, Lv W. High temperature and high humidity reduce the 
transmission of COVID-19.

Available at SSRN 3551767.

2020 Mar 9.

10. Li Q, Guan X, Wu P, Wang X, Zhou L, Tong $\mathrm{Y}$ et al; Early Transmission Dynamics in Wuhan, China, of Novel Coronavirus-Infected Pneumonia. N. Engl. J. Med. 2020 Jan 29

11. Phan LT, Nguyen TV, Luong QC, Nguyen TV, Nguyen HT, Le HQ, Nguyen TT, Cao TM, Pham QD. Importation and human-to-human transmission of a novel coronavirus in Vietnam. New England Journal of Medicine. 2020 Feb 27;382(9):872-4.

12. Chen C, Gao G, Xu Y, Pu L, Wang Q, Wang L, Wang W, Song Y, Chen M, Wang L, Yu F. SARS-CoV-2-Positive Sputum and feces after conversion of pharyngeal samples in patients with COVID-19. Annals of internal medicine. 2020 Mar 30.

13. Bai Y, Yao L, Wei T, Tian F, Jin DY, Chen L, Wang M.
Presumed asymptomatic carrier transmission of COVID-19. Jama. $2020 \quad$ Apr 14;323(14):1406-7.

14. Ebrahim SH, Ahmed QA, Gozzer E, Schlagenhauf P, Memish ZA. Covid-19 and community mitigation strategies in a pandemic.

15. Price KR, Lewis J, Wyatt GM, Fenwick GR. Review article Flatulence-Causes, relation to diet and remedies. Food/Nahrung. 1988;32(6):609-26.

16. Tangerman A. Measurement and biological significance of the volatile sulfur compounds hydrogen sulfide, methanethiol and dimethyl sulfide in various biological matrices. Journal of Chromatography B. 2009 Oct 15;877(28):3366-77.

17. Tomlin J, Lowis C, Read NW. Investigation of normal flatus production in healthy volunteers. Gut. 1991 Jun 1;32(6):665-9.

18. Prasad GA, Alexander JA, Schleck CD, Zinsmeister AR, Smyrk TC, Elias RM, Locke III 
GR, Talley NJ. Epidemiology

of eosinophilic esophagitis over three decades in Olmsted County, Minnesota. Clinical Gastroenterology and Hepatology. 2009 Oct 1;7(10):1055-61.

19. Levitt MD: Intestinal gas, in Feldman M, Scharschmidt BF, Sleisenger $\mathrm{MH}$ (eds): Gastrointestinal and Liver Disease, ed 6. Philadelphia, WB Saunders Co, 1998, pp 153160.

20. Suarez FL, Levitt MD: An understanding of excessive intestinal gas. Curr Gastroenterol Rep 2:413-419, 2000.

21. Bell AJ, Ciclitira PJ: Managing bloating, flatus and flatulence. Practitioner 244:301-311, 2000.

22. Poderoux P, Gulchin EA, Shezang L, et al: Esophageal bolus transit imaged by ultrafast computerized tomography. Gastroenterology 110:14221428, 1996.

23. Levitt MD, Furne J, Aeolus MR, et al: Evaluation of an extremely flatulent patient: Case report and proposed diagnostic and therapeutic approach. Am J Gastroenterol 93:2276-2281, 1998.

24. Levitt MD: Volume and composition of human intestinal gas determined by means of an intestinal washout technique. N Engl J Med 284:1394-1398, 1971.

25. Richards EA, Steggerda FR: Production and inhibition of gas in various regions in the intestine of the dog. Proc Soc Exp Biol Med 122:573-576, 1966.

26. Suarez FL, Springfield J, Furne $\mathrm{JK}$, et al: Gas production in humans ingesting a soybean flour derived from beans naturally low in oligosaccharides. Am J Clin Nutr 69:135-139, 1999.

27. Suarez FL, Springfield J, Levitt MD: Identification of gases responsible for the odour of human flatus and evaluation of a device purported to reduce this odour. Gut 43:100-104, 1998. 
28. Mercer, Bobby (April 18, 2009). How Do You Light a Fart?: And 150 Other Essential Things Every Guy Should Know about Science. Adams Media.

p. 71. ISBN 9781440519871. Retrieved October 2, 2014.

29. Miller TL; Wolin MJ; de Macario EC; Macario AJ (1982). "Isolation of Methanobrevibacter smithii from human faeces". Applied and

Environmental

Microbiology. 43 (1): 227-

32. PMC 241804. PMID 67989

32.

30. Pimentel, Mark; Robert P Gunsalus; Satish SC Rao; Husen Zhang (2012). "Methanogens in Human Health and Disease". The American Journal of Gastroenterology Supplements. 1 (1): $28-$ 33. doi:10.1038/ajgsup.2012.6.

31. Giffard CJ, Collings SB, Stoodley RM: Ability of an anti1080 Small Animal/Exotics Compendium December 2001 flatulence treat to reduce the hydrogen sulfide content of canine flatulence. J Vet Intern Med 14:349, 2000.

32. Reddy NR, Salunkhe DK, Sharma RP. Flatulence in rats following ingestion of cooked and germinated black gram and a fermented product of black gram and rice blend. Journal of Food Science. 1980 Sep;45(5):1161-4.

33. Rao SS. Belching, bloating, and flatulence: how to help patients who have troublesome abdominal gas. Postgraduate medicine. 1997 Apr 1;101(4):263-78.

34. https://www.abc.net.au/radio/pr ograms/coronacast/no-barebottoms-norman-swanweighsin/12154256

35. https://twitter.com/andrewjtagg /status/1247087532367441920 ?s=20\&utm

36. https://ourcommunitynow.com/ news-world/can-covid-19-bespread-through-farts-theseaustralian-doctors-suggest-so 37. Tang, A., et al. "Detection of Novel Coronavirus by RT-PCR 
in Stool Specimen from Asymptomatic Child, China." Emerging infectious diseases 26.6 (2020).

38. https://www.southnassau.org/s n/find-a-doctor/glatt-aaron-emd-facp-fidsa-fsheachairmandepartm 26

39. https://nypost.com/2020/04/20/ can-the-coronavirus-be-spreadthrough-farts

40. https://health.mountsinai.org/bl og/what-shouldgastroenterologists-andpatients-know-aboutcovid19

41. Song Y, Liu P, Shi XL, Chu YL, Zhang J, Xia J, Gao XZ, Qu T, Wang MY. SARS-CoV-2 induced diarrhoea as onset symptom in patient with COVID-19. Gut. 2020 Mar 4.

42. Pan L, Mu M, Yang P, Sun Y, Wang R, Yan J, Li P, Hu B, Wang J, Hu C, Jin Y. Clinical characteristics of COVID-19 patients with digestive symptoms in Hubei, China: a descriptive, cross-sectional, multicenter study. The American journal of gastroenterology. $2020 \quad$ Apr $14 ; 115$.

43. Lin L, Jiang X, Zhang Z, Huang S, Zhang Z, Fang Z, Gu Z, Gao L, Shi H, Mai L, Liu Y. Gastrointestinal symptoms of 95 cases with SARS-CoV-2 infection. Gut. 2020 Apr 2.

44. Hot air? BMJ. 2001 Dec 22;323(7327):1449. PMCID: PMC1121900.

45. Greenstone M, Nigam V. Does Social Distancing Matter?. University of Chicago, Becker Friedman Institute for Economics Working Paper. 2020 Mar 25(2020-26).

46. Wilder-Smith A, Freedman DO. Isolation, quarantine, social distancing and community containment: pivotal role for old-style public health measures in the novel coronavirus (2019-nCoV) outbreak. Journal of travel medicine. 2020 Mar;27(2):taaa020.

47. D'Amico F, Baumgart DC, Danese S, Peyrin-Biroulet L. Diarrhea during COVID-19 infection: pathogenesis, 
epidemiology, prevention and management. Clinical

Gastroenterology and

Hepatology. 2020 Apr 8.

48. Colson P, Rolain JM, Lagier JC,

Brouqui P, Raoult D.

Chloroquine and

hydroxychloroquine as

available weapons to fight COVID-19. Int J Antimicrob Agents. $2020 \quad$ Mar

4;105932(10.1016).
49. Casadevall A, Pirofski LA. The convalescent sera option for containing COVID-19. The Journal of clinical investigation. 2020 Apr 1;130(4):1545-8.

50. Hartl T, Wälde K, Weber E. Measuring the impact of the German public shutdown on the spread of COVID19. Covid economics, Vetted and realtime papers, CEPR press. 2020 Apr 3;1:25-32. 